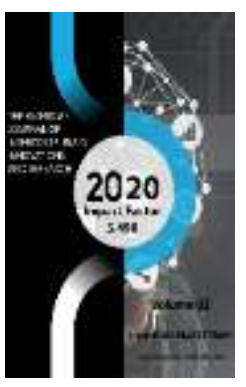

\title{
Unpredictable Testimony Of Cell Divider Polymers Coming About Because Of Flawed Cellulose Synthase Buildings
}

\author{
Adeseye Oluyori Omole \\ Dept. Of Biological Sciences, Associate Professor, Yobe State University, Nigeria
}

Journal Website: http://usajournalshub.c om/index,php/tajiir

Copyright: Original content from this work may be used under the terms of the creative commons attributes 4.o licence.

\section{ABSTRACT}

The crystalline cellulose microfibril is framed by the unconstrained relationship of around $36 \beta$-Dglucan chains, which are at the same time blended by a huge film confined multi-catalyst cellulose synthase complex. Antisense innovation has been recently utilized independently on two of the constituent cellulose synthase synergist subunits of the complex in potato (Solanum tuberosum ), in particular CesA2 and CesA4, to create potato tuber cell dividers with decreased cellulose content. Hereditary intersection of two transgenic potato lines csr2-1 and csr4-8 was completed to research the impacts of two imperfect CesAs in the equivalent hereditary foundation, as for cellulose statement in the potato tuber cell dividers.

\section{KEYWORDS}

Cell divider, cellulose synthase, polysaccharide testimony, Solanum tuberosum.

\section{INTRODUCTION}

The crystalline cellulose microfibril is for the unconstrained relationship of around $36 \beta$-Dmost part accepted to be framed by the glucan chains, which are all the while combined 
by a huge layer limited multi-compound cellulose synthase complex that was

uncovered by microscopy. These transgenic potato tuber clones were acquired by changing the potato plant with antisense/sense builds of a total CDNA of potato cellulose synthase, (ASCesA3/SE-CesA3) and antisense develops of the class-explicit districts (CSR) of four comparing potato cellulose synthase qualities ( $C S R 1,2,3$ and 4).

Two transgenic lines csr2-1 and csr4-8, which demonstrated extensive cellulose decrease (40\% and 60\%, separately) in their tuber cell dividers were recognized by the anthrone colorimetric measure (Omole et al ., 2004). These two lines additionally assembled in a similar bunch following Fourier Change Infra Red Spectroscopy and Head Part Examination. These perceptions prompted the theory that CesA 2 and Ces $\mathrm{A} 4$ proteins are most likely piece of a similar complex. Consequently the enthusiasm to investigate the chance of accomplishing twofold transformants with joined impacts of the two transgenes on cellulose affidavit.

\section{MATERIALS AND STRATEGIES}

\section{Plant Material And Development Conditions}

Potato ( Solanum tuberosum ) plants utilized for the cross conveyed, in antisense direction, csr2 arrangement of the potato CesA2 quality (increase number AY221089) and the csr4 succession of the CesA4 quality (promotion number AY221088) as prior detailed (Omole et al ., 2008). So as to perform chemical treatment on stem area, an alternate technique for obsession and installing in correlation with the one portrayed before was fundamental. Tuber tests were fixed in 5\% glutardialdehyde in $0.1 \mathrm{M}$ phosphate support, containing $0.1 \%$ Triton $\times 100$ for 2 hours. The

examples were then washed with the cradle without glutardialdehyde, and got dried out in an ethanol arrangement $(0,10,30$, half ethanol containing $10 \mathrm{mM}$ dithiothreitol (DDT)) and implanted in butyl-methyl methacrylat (BMM) as depicted somewhere else (Ban et al ., 1992; G, 1989). 4 micron-thick tissue areas were produced using the BMM-inserted stem tests and mounted on glass slides. The installing material was expelled from the segments with $\left.\mathrm{CH}_{3}\right)_{2} \mathrm{CO}$, and afterward the segments were promptly washed with $25 \mathrm{mM}$ citrate cushion $\mathrm{pH} 3.5$.

\section{Light Microscopy}

One mm-thick potato tuber areas were fixed, dried out and implanted in Technovit 7100 gum (Kuroiwa et al . 1990) as prior depicted by Obembe and Vincken (2008). 4 micron-thick tissue segments were recolored with calcofluorwhite $(0.04 \%)$ and inspected by light magnifying lens. Each minute assessment was done in sets of three (tuber areas of three individual plants from each clone).

To confirm the perception made on the calcofluorwhite-recolored csr2 tuber areas, crisp recoloring was made for csr2 and the control tuber segments with $0.1 \%$ aniline blue in $0.1 \mathrm{M} \mathrm{K} \mathrm{K}_{3} \mathrm{PO}_{4}$ and inspected under fluorescence magnifying instrument. This was then trailed by calcofluorwhite recoloring of the aniline blue-recolored tuber segments. They were then inspected under fluorescence magnifying lens for differential recoloring designs. BMM-implanting and xyloglucanase treatment 


\section{RESULTS AND CONVERSATION}

Fluorescence microscopy with calcofluor white recoloring uncovered a surprisingly solid fluorescence in cell divider corners of the csr2 tubers. This unpredictable testimony of divider materials was seen in all tissues with the exception of the epidermis. Moreover, the fluorescence in the cell dividers of csr2 tubers is significantly less conspicuous and for the most part lopsided when contrasted with the control, the csr4 and the twofold csr2/csr4 transformants. This solid fluorescence in cell divider corners of the csr2 potato tuber is demonstrative of particular statement of cellulosic polymers, albeit one can't avoid the likelihood that it may be xyloglucan. Henceforth, check that the watched fluorescence in cell corners was really from cellulose store since calcofluor white stains both cellulose and other Bglucan chain polysaccharides, for example, callose and xyloglucan (Wood, 1980). So as to segregate among cellulose and callose store.

\section{CONCLUSION}

In general, these outcomes confirm the way that impedance to an essential cell divider complex could have huge impact on cellulose testimony. They have additionally revealed more insight to the elements of cellulose affidavit. Be that as it may, more work despite everything should be done to unwind the specific hidden instruments of rosette get together and the exact idea of cellulose affidavit.

\section{REFERENCES}

1. Tornielli GB, Lanfaloni L, (2004) Opposition against herbicide isoxaben and cellulose lack brought about by unmistakable changes in same cellulose synthase isoform CESA6. Plant Physiol . 218, 182-190.

2. Howells RM, Huttly $A K$, Vickers $K$ (2009) The cellulose synthase complex: an unpredictable polymerisation driven supramolecular engine. Biophys. J . 85, 1266-1273.

3. Reale L, Tornielli GB (1995) The creation of the design of the plant cell divider: How cells misuse geometry. Proc. Natl. Acad. Sci. USA . 75, 215-219.

4. Kuroiwa $\mathrm{T}$, Kuroiwa $\mathrm{H}$, Mita $\mathrm{T}$ and Fujie M (2003) PROCUSTE1 encodes a cellulose synthase required for typical cell lengthening explicitly in roots and dim developed hypocotyls of Arabidopsis . Plant Cell . 21, 209-223.

5. Jauneau A, Vernhettes S, (2005) Control of cellulose synthase complex limitation in creating xylem. Plant Cell $16,140-148$.

6. Tsekos I (1985) Immunofluoresence confinement of microtubules in plant root tips implanted in Butylmethyl methacrylate. Cell Biol. Int. Rep . 10, 1745 .

7. Zenoni $S$, Hocart $\mathrm{CH}$, Arioli $\mathrm{T}$ and Williamson RE (2004) A change in an Arabidopsis ribose 5-phosphate isomerase lessens cellulose combination and is safeguarded by exogenous uridine. Plant J . 28, 106-118. 
8. Yim K (2010) The cellulose Catch 22 a basic atom, complex biosynthesis. Curr. Opin . Plant Biol . 14, 320-326.

9. Obembe $\mathrm{OO}$ and Vincken JP (2007) Dimerization of cotton fiber cellulose synthase reactant subunits happens by means of oxidation of the zincrestricting spaces. Proc. Natl. Acad. Sci. USA . 69, 2109-2114. 